Technical Note

\title{
Urban renewal evaluation for traditional neighborhoods based on sustainable community development rating system: $A$ case study in Zhejiang, China
}

\author{
K. Wang ${ }^{1}$ and Z. Y. Cao ${ }^{2}$
}

\section{ARTICLE INFORMATION}

\section{Article history:}

Received: 27 January, 2015

Received in revised form: 23 April, 2015

Accepted: 07 May, 2015

Published on: June, 2015

\section{Keywords:}

Urban renewal evaluation

Traditional neighborhood

Sustainable community development

Rating system

\begin{abstract}
A B S TRACT
Lacking evaluation systems, urban renewal for traditional neighborhoods has caused serious problems, hindering the urbanization process in East China. Based on the study of the evaluation system with regard to traditional neighborhood renewal and sustainable community development, this paper compares two current sustainable community development rating systems and the adjusting tasks and achievements in the case project. This paper argues that introducing a sustainable community development rating system is a feasible and workable approach to urban renewal evaluation for the traditional neighborhood. The paper extracts the related criteria from the two rating systems and applies them to the design in the case project. The subsequent results verify the necessity and practicality of this approach.
\end{abstract}

1. Five task adjustments in Yongkang "Old Town Characteristic Cultural Neighborhood" renewal design

\subsection{Project description}

Yongkang, Zhejiang Province, China "Old Town Characteristic Cultural Neighborhood" renewal design was launched in August 2010 with an area of 4.38 ha. The project is located in the "old city" section of Yongkang, which is also the core area and commercial center, and records the original development, prosperity and decline of the city (Fig. 1). The project retains a certain number of historically and culturally valued buildings and neighborhood after the loss of a large number of houses for old city renewal. In summary, the Yongkang project can be defined as a typical traditional neighborhood renewal urban design.

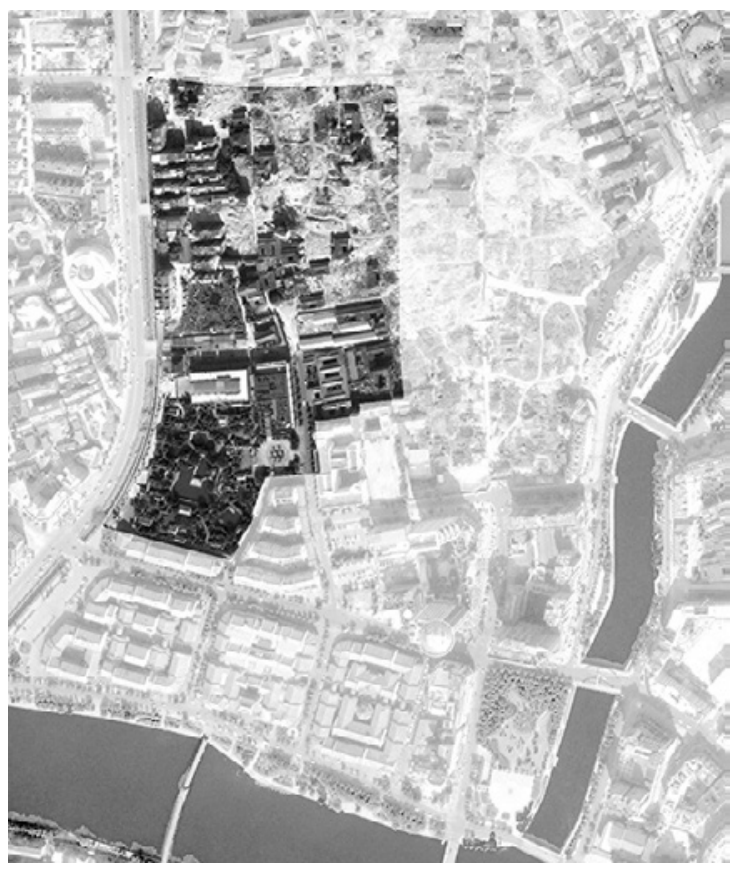

Fig. 1. Location of Yongkang Project.

\footnotetext{
${ }^{1}$ Lecturer, Department of Architecture, Zhejiang University, Hangzhou, CHINA, wangka@zju.edu.cn

${ }^{2}$ Lecturer, Department of Architecture, Zhejiang University, Hangzhou, CHINA, 373102804@qq.com Note: Discussion on this paper is open until September 2015
} 


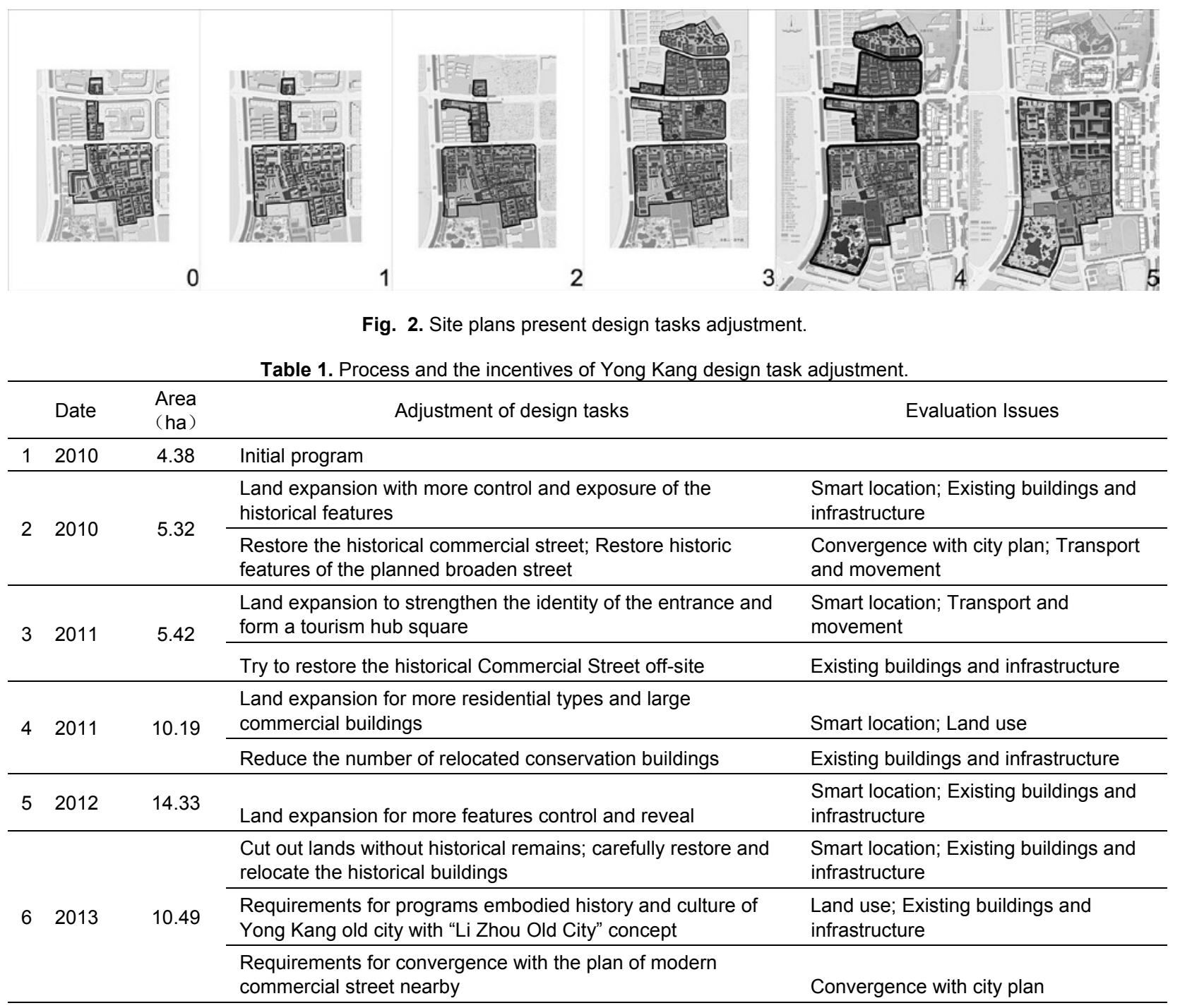

\subsection{Design tasks adjustment}

The design tasks have so far been adjusted five times during the process of Yongkang project as shown in Fig. 2. These adjustments are not a result of the design techniques, but rather due to the design tasks which are determined by the evaluation issues (Table 1). The overall evaluation issues are not changed while each particular issue was emphasized following each task adjustment. These kinds of problems are typical in urban renewal of traditional neighborhoods. They occur because of the lack of scientific evaluation systems, which include the following two points:

Lack of an integral evaluation main body. The leader of Yongkang project is the Planning Bureau using as consultant the Administration of Cultural Heritage. However, the latter only provided information at the beginning and joined the evaluation main body in the late stage of design together with local residents and folk intellectuals. Each group has different interests and values, and thus, different evaluation criteria. Therefore, when the main body changes, the evaluation criteria changes as well, which led to the adjustments of the design tasks. For example, regarding land use evaluation, in the beginning it was a priority to improve the economic vitality and development of residential function, but the higher priority later became the embodiment and preservation of the history and culture of Yongkang old city.

Lack of specific indicators and relevant weights for evaluation. "Land use" and "existing buildings and infrastructure" are issues which appeared at each stage of task adjustment. The former pays more attention to the control and exposure of the features of the land. The latter pays more attention to the relocation and conservation of existing buildings. These evaluations lack specific indicators and weightings when they contradict others. This led to a design strategy with several proposals presented and evaluated against each other each time which cost a large amount of resources, especially time. 


\subsection{Study significance and method}

Like most existing traditional neighborhoods in East China, the Yongkang project is located next to a body of water and has a lowland characteristic, which makes this kind of neighborhood development more dependent on the eco environment. Therefore, an important issue in studying urban renewal evaluation for traditional neighborhood is to maintain sustainable development of the communities in lowland areas. The study method will also be focused on sustainable development evaluation. Although each adjustment of the Yongkang project contributes to the accumulation of design experience and comprehensive in-depth understanding and thinking, it costs a large amount of resources and delays the design process and the progress of the city development. This is the reason why it is necessary to establish a scientific evaluation system for traditional neighborhood renewal. Most evaluations on the project consider historical, cultural, as well as economic positions. The evaluation systems are independent from each other and cannot be unified. The evaluation results often fail to provide proper guidance. Therefore, a scientific, objective and integrated evaluation system should be formulated. From a sustainable perspective, it is possible to integrate various issues into a unified evaluation system, allowing quantifiable results for guidance to be more feasible (Zhang et al., 2010). A traditional neighborhood, as a kind of special urban space, is more conducive than other urban areas to extraction and scientific evaluation (Wang et al., 2005).

\section{Issues about urban renewal for traditional neighborhood}

Traditional neighborhoods are generally located in the center of the old city, including historical and cultural blocks and an historic area ( $\mathrm{Wu}, 2009)$. Principles for conservation and renewal of these blocks and area are well agreed upon for their irreplaceable historical heritage. So the scope of this study is about neighborhoods that have a number of historical structures, but have less integrity than the traditional features and typical properties of structures of historical significance. Issues about their renewal design include the following four points:

Other than conservation and renewal of single buildings, it puts more emphasis on enhancing the overall quality of the neighborhood. The distinction between overall environment and the simple sum of individual buildings has become a consensus. Therefore, although it is necessary to consider the individual buildings, the major consideration of renewal is at the community level. It also includes the convergence with the overall city plan because traditional neighborhoods are parts of the city.

Other than conservation of an historic area, it puts more emphasis on community development. G.Y. Huang (1994) put forward that urban renewal should take improvement of the environment as an important objective. G.Y. Zhu (1998) and Q. Zha (2000) proposed and stressed the method of reasonable development and utilization of traditional architectural heritage and evaluation. According to the view of PerformanceOriented Design, which is widely accepted as urban design evaluation criteria, traditional neighborhoods need to host the new city life, and the related evaluation approach should be updated accordingly (Li et al., 2012).

Other than metro development, it puts more emphasis to the evaluation of the built environment. It is gradually realized that the built environment is not limited to physical space, it also includes an historical context. The latter should be converted to indicators when it is introduced to form a complete evaluation system along with other indicators. This is a problem which needs to be addressed in the traditional neighborhood renewal. In this respect Japanese environment reservation theory and practice can be a good reference (Zhang, 2000). It includes the idea that the value of an historical environment and ongoing conservation efforts will enhance the value of investment. It further maintains that the social engineering intervention to "solution investigation" requires clarifying social problems (social economy, management, city, regional, international relations among other aspects) through a technological approach such as analysis, mathematics and measurement (Wu et al., 2011).

Other than simple conservation or new development, traditional neighborhood renewal is a dynamic conversion process. Couch (1990) emphasized that urban renewal is a dynamic process based on the conversion of physical space (demolition and reconstruction, repair, etc.), land use and the function of buildings (from one to another more efficient kind), or the intensity of conversions. Most of these conversions are occurring in the city core areas on the valued historic structures. So the process made a great impact on the city, which should be concerned with urban design.

\section{Sustainable community development rating system}

Sustainable community development rating system (hereafter SCDRS) is a scientific evaluation method of 
urban design from a low-carbon eco perspective. The corresponding evaluation system is also one of the current planning and design standards. Considering the historic characteristics of a traditional neighborhood and its renewal issues, it is suitable to introduce SCDRS into urban renewal evaluation for a traditional neighborhood which is a special type of community. The most established and recognized rating systems currently used in many countries include "BREEAM-C" (Britain), "LEEDND" (America), "EEWH-EC" (Taiwan) and "DGNB-UD" (Germany). "BREEAM-C" is concerned more about the community renewal projects than the others. Its evaluation criteria is also concerned more about urban context heritage and convergence between communities and city. "LEED-ND" is established based on new urbanism and smart growth theory. These two criteria aim to control urban expansion and achieve compact development, which has significance for the evaluation of traditional neighborhoods renewal.

Study on the rating system indicators in China is still in the initial stage. The "Eco-communities Technology Evaluation Manual in China" (hereinafter referred to as the Manual) is the most widely used in China for planning, construction and operation in residential areas. But it puts much more emphasis on buildings than on neighborhood plans, humanities and ecological environment (Yang et al., 2011).

Some scholars have found problems with the dynamic evaluation of community development. Especially in urban renewal, the choice of indicators should reflect the dynamic development of the old communities (Gao and Tian, 2007). From the view of the whole sustainable evaluation system, the evaluation of historical structures is on the community level (LEED system includes LEED for Existing Buildings: Operations \& Maintenance Core Committee, but is mainly for building operation and maintenance and not cultural value). So the evaluation of the case in this paper is mainly based on sustainable communities' criteria of BREEAM-C and LEED-ND.

\section{Evaluation and principles based on SCDRS}

\subsection{Introduce SCDRS into evaluation of traditional neighborhood renewal}

There are three steps for the introduction of SCDRS (Fig. 3). The first step is to make a comparison between Yongkang adjustments evaluation criteria and the two prominent SCDRS issues and credits. The comparison shows that the issues considered and taken as the evaluation criteria in the project adjustments can also be found in SCDRS. So the SCDRS can support the evaluation of traditional neighborhood renewal. The second step is to extract the issues and credits especially for the traditional neighborhood renewal issues from SCDRS. The third step is to adjust the design based on the evaluation criteria and credits, and then verify the necessity and practicality of this approach.

The results of the first two steps are shown as Table 2. The left column presents related issues extracted and integrated from BREEAM-C and LEED-ND. The middle column presents the corresponding credits to both rating issues and the Yongkang criteria. This column also shows weighting of the rating criteria of BREEAM-C and LEED-ND especially for traditional neighborhood renewal evaluation. The right column is integrated by two parts; one is evaluation criteria used in the case project which can also be found in BREEAM-C and LEED-ND, the other is criteria of traditional neighborhood renewal evaluation which derived from BREEAM-C and LEED-ND. It was found that the proportion of total related credits is $57.9 \%$ (BREEAM-C) and 66.0\% (LEED-ND). The criteria directly related to traditional neighborhood renewal are up to 23 items. Based on the comparison, the design evaluation criteria are proposed for traditional neighborhood renewal, showing that the sustainable community development rating criteria not only can be a strong basis for evaluation of traditional neighborhood renewal, but also plays a guiding role in the design process.

\subsection{Traditional neighborhood renewal design based on sustainable evaluation system}

Under the guidance of the above evaluation criteria, the 6th adjustment of Yongkang project was re-examined based on sustainable evaluation. Design is also adjusted accordingly as follows (Fig. 4).

1. Architectural heritage: Reduce the number of relocated existing buildings. If relocation is necessary, it should follow the principle of the nearest and centralized arrangement so as to reduce the impact of construction.

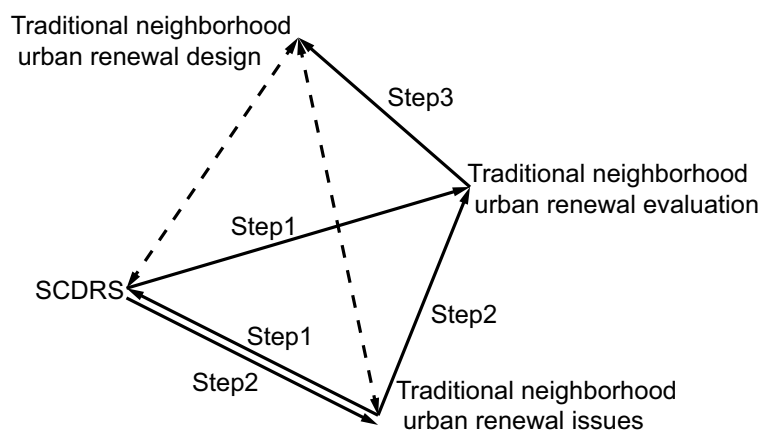

Fig. 3. Three steps for the introduction of SCDRS. 
Table 2 Evaluation criteria of traditional neighborhood renewal based on SCDRS.

( $\star$ means mandatory standards, $\circ$ means no credits,- means not required)

\begin{tabular}{|c|c|c|c|c|}
\hline \multirow{2}{*}{\multicolumn{2}{|c|}{ SCDRS Issues }} & \multicolumn{2}{|c|}{ Credits } & \multirow{2}{*}{ Criteria of traditional neighborhood renewal evaluation } \\
\hline & & BREEAM & LEED & \\
\hline Governance & $\begin{array}{l}\text { Evaluation main } \\
\text { body }\end{array}$ & $\star 9.3 \%$ & $2 \%$ & $\begin{array}{l}\text { To ensure community involvement and leadership in all stages of the } \\
\text { renewal process }\end{array}$ \\
\hline \multirow{3}{*}{ Location } & \multirow{2}{*}{$\begin{array}{l}\text { Land scale and } \\
\text { properties }\end{array}$} & $\star 2.1 \%$ & $\star 12.0 \%$ & Renovate sites need mediation while limiting the expansion \\
\hline & & $1.4 \%$ & $3.0 \%$ & enable residents from a wide range of economic levels \\
\hline & Show features & $\circ$ & - & Consider features show about the site edge \\
\hline \multirow{4}{*}{$\begin{array}{l}\text { Historical } \\
\text { remains }\end{array}$} & Existing buildings & $\star 3.40 \%$ & - & $\begin{array}{l}\text { Control relocated conservation; minimize construction interference; take } \\
\text { account of the embodied carbon in existing buildings and infrastructure } \\
\text { and to promote their re-use where possible. }\end{array}$ \\
\hline & $\begin{array}{l}\text { Existing roads and } \\
\text { infrastructure }\end{array}$ & $\star 0.9 \%$ & $2.0 \%$ & $\begin{array}{l}\text { Try to keep the original street network, full use of existing infrastructure } \\
\text { under roads; adjust micro-weather based on the experience of traditional } \\
\text { neighborhood layout }\end{array}$ \\
\hline & Original terrain & $0.8 \%$ & - & keep original terrain \\
\hline & Local features & $0.9 \%$ & - & Use local materials to show local features \\
\hline \multirow{7}{*}{ Land use } & Intensity & - & $6.0 \%$ & Compact development with use of underground spaces \\
\hline & \multirow{6}{*}{$\begin{array}{l}\text { Land use related } \\
\text { with historical } \\
\text { remains }\end{array}$} & $8.9 \%$ & - & Create a healthy economy based on cultural context \\
\hline & & $5.9 \%$ & - & Provide training and skill opportunities based on cultural context \\
\hline & & $2.7 \%$ & - & The housing type and tenure is based on the needs in the local area \\
\hline & & $\star 1.4 \%$ & $7.0 \%$ & $\begin{array}{l}\text { Based on function conversion of existing buildings, provide affordable } \\
\text { rented, social rented and intermediate affordable housing }\end{array}$ \\
\hline & & $2.7 \%$ & $6.0 \%$ & Public facilities meet the needs of all levels with accessibility \\
\hline & & $2.7 \%$ & - & $\begin{array}{l}\text { Public spaces designed based on originals and meet the needs of climate } \\
\text { comfort and field identification }\end{array}$ \\
\hline \multirow{4}{*}{$\begin{array}{l}\text { Transport } \\
\quad \text { and } \\
\text { movement }\end{array}$} & Parking & $1.4 \%$ & $1.0 \%$ & $\begin{array}{l}\text { Reduced parking footprint, parking area well integrated into the } \\
\text { development, comfortable bicycle parking }\end{array}$ \\
\hline & \multirow{3}{*}{$\begin{array}{l}\text { Movement method } \\
\text { and spaces }\end{array}$} & $3.2 \%$ & $\star 2.0 \%$ & $\begin{array}{l}\text { Provide closely and open community transport; Assess trends and set } \\
\text { aside transportation space }\end{array}$ \\
\hline & & $3.2 \%$ & $12.0 \%$ & Provide walkable street based on the cultural context \\
\hline & & $2.1 \%$ & $7.0 \%$ & Accessibility of bus station \\
\hline \multirow{4}{*}{$\begin{array}{l}\text { Greens and } \\
\text { landscape }\end{array}$} & $\begin{array}{l}\text { Greens and the } \\
\text { historical remains }\end{array}$ & $1.0 \%$ & - & $\begin{array}{l}\text { Important existing landscape features and landmarks will be preserved in } \\
\text { the new development; ensure the accessibility of green spaces }\end{array}$ \\
\hline & \multirow{3}{*}{$\begin{array}{l}\text { Landscape and } \\
\text { the traditional } \\
\text { features }\end{array}$} & $1.2 \%$ & - & The continuity of the original species; ensure the ecological needs \\
\hline & & - & $2.0 \%$ & Set boulevards and greens on buildings based on traditional features \\
\hline & & $2.7 \%$ & $1.0 \%$ & Landscape design with efficient water use \\
\hline \multicolumn{2}{|c|}{ Total related credits } & $57.9 \%$ & $66.0 \%$ & \\
\hline
\end{tabular}

2. Original streets network: Try to keep the original streets and open spaces, extend the north-south streets network which is emphasized in traditional arrangement. Demolish the living quarters in the east and west wings which has poor qualities of structure and features. Then plan park and large courtyard style buildings to ensure natural convergence of traditional and modern streets networks.

3. Original terrain: Keep original terrain low in the southwest and high in the northeast. Take the advantages of semi-underground and overhead construction in the northeast to solve the disparity between original terrain and newer road networks.

4. Local features: Restore the traditional functions and spaces of commercial chambers.

5. Intensity: Replace the antique commercial space with parks considering that the large number of plots with the same function have been built on the south side of the project. Set semi-underground parking and commercial area in the east and west wings after the living quarters have been demolished so as to make full use of underground space.

6. Land use: Increase integrated houses and modern public facilities and spaces. Convert the functions of existing buildings to special retail and commercial chambers with exhibition features. Provide appropriate technical training to increase employment of labor and improve economic viability.

7. Parking: In addition to a large scale underground parking area in east and west wings, increase small scale ground parking areas at plaza, courtyards, overhead constructions and rear lanes. Encourage green modes of transportation with indoor bicycle parking areas integrated with the buildings.

8. Movement spaces: Ensure the close spatial contact between new streets and existing buildings based on a full study of the latter. 


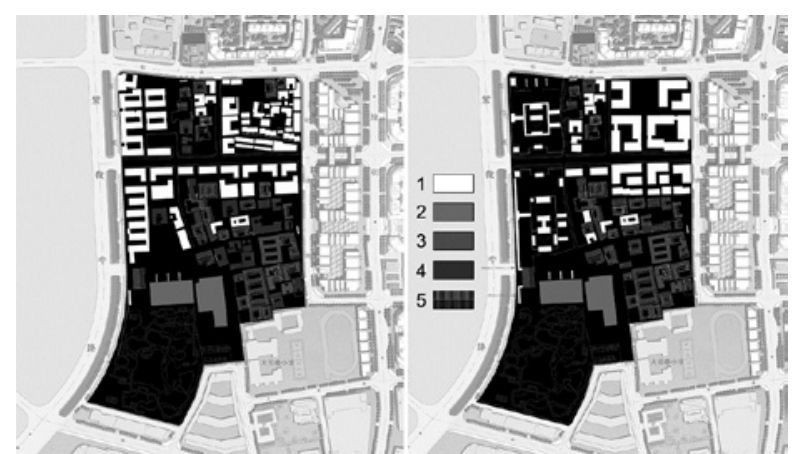

Fig. 4. Comparison between the $5^{\text {th }}$ and $6^{\text {th }}$ adjustment (1planned building, 2- existing new building, 3- rebuilt old building, 4- relocated old building, 5- preserved old building ).

9. Greens and landscape: Plan a park in the west wing after demolishing living quarters to ensure enough green land for the surrounding areas. It also opens the view of the traditional features at the center of the site from the main road at the west side.

The historical structures are fully conserved and shown after the adjustment. A natural convergence and transition has formed between it and the modern city. It also ensures the integration of modern city life. At the same time, the old neighborhood itself showed rich levels of historical features and spatial relationships when it provides for an enriched city life.

\section{Conclusions}

The study of design adjustments of Yongkang project opens the door to introduce a sustainable community development rating system to evaluate traditional neighborhoods renewal. It also verifies the feasibility and necessity of the traditional neighborhood renewal design from a low-carbon eco perspective. The analysis result of this paper presents that as a special kind of sustainable development plan, the traditional neighborhoods renewal can be evaluated by the criteria of SCDRS which also can be implicated to the renewal design.

It needs long term research and engineering feedback to establish the sustainable community development criteria system based on historical structures and the modern urban environment in China. On the other hand, the historical structures bare more local features. So the evaluation should be made with full integration of the features of the project playing the guiding role in design process.

\section{Acknowledgements}

This paper is supported by the Zhejiang Provincial Natural Science Foundation (LY13E080004).

\section{References}

Couch C., 1990. Urban renewal: Theory and practice. Hampshire, Macmillan Education Ltd.: pp1.

Gao, J. X. and Tian, M. R. 2007. Model of sustainable development of communities- discussion on "ecological communities". China Development, 7 (4): 6-10.

Huang, G. Y., 1994. Some experiences and problems in China old city reconstruction. J. Chongqing Inst. of Archit \& Engin, 16 (3): 77-83.

Li, T. and Liu, C. H., 2012. Establishing a performanceorientated Chinese green building assessment system. Architectural Journal, 2012 (S2): 182-185.

Wang, Y., Wang, X. M. and Zhu, Y. L., 2000. Study of urban renewal system based on sustainable development. J. of HUST. (Urban Science Edition), 22 (4): 40-43.

$\mathrm{Wu}, \mathrm{Y} ., 2009$. Comparative research on the investigation in the historical district between Japan and China. Ph.D. Thesis, Zhejiang University. Hangzhou, China (unpublished).

Wu, Y., Shen, J. H. and Xu L. 2011. The Mechanism of the investigation in "the preservation district of historical buildings" in Japan and its inspiration for China. Urban Planning International, 26 (1): 77-81.

Yang, M. H., Bai, Y. and Zeng, H. 2011. Optimization strategies for eco-communities assessment system in China: based on LEED-ND and BREEAMCommunities. Urban Studies, 18 (12): 27-31.

Zhang, J. K., Feng, Y. J. and Liu, Z. G., 2010. On evaluation of renovation sustainability of old city on DPSIR model: A case study of Qinhuai district, Nanjing city. J. Nanjing Agricultural University (Social Sciences Edition), 10 (4): 80-87.

Zhang, S., 2000. Theory and practice of historic environment preservation in Japan. Tsinghua Univ. (Sci \& Tech), 40 (S1): 44-48.

Zha, Q., 2000. Availability evaluation for architectural heritage. Architectural Journal, 2000 (11): 48-51.

Zhu, G. Y., Fang, Q. and Lei, H. M., 1998. An Exploration for evaluation of architectural heritage. New Architecture, 1998 (2): 26-28.

BREEAM Communities Technical Manual, SD202 Version: 2012 Issue: 0.1 Issue Date: 21/02/2013. http://www.breeam.org/bre_PrintOutput/BREEAM_Co mmunities_0_1.pdf.

LEED 2009 for Neighborhood Development Rating System-current version. http://www.usgbc.org/resources/leed-neighborhooddevelopment-v2009-current-version. 